\title{
A positive-sequence current based directional relaying approach for CCVT subsidence transient condition
}

\author{
Monalisa Biswal* and Sandeep Biswal
}

\begin{abstract}
In this work, a directional relaying algorithm is proposed for transmission line to prevent relay maloperation during coupling capacitor voltage transformer (CCVT) subsidence transient. The effect of CCVT subsidence transient during single-pole-tripping condition is highlighted in this paper. The proposed method which is based on phase angle difference of post fault and prefault positive sequence current can help the directional relay to take accurate decision during erroneous CCVT secondary response. The available CCVT model in PSCAD is not able to generate significant subsidence transient in the secondary side. So, a new CCVT model is developed in EMTDC/PSCAD domain for transient response analysis and to check the relay operation. Next, the performance of different voltage and current information based directional relaying techniques have been analyzed and compared with the proposed method. The results are evaluated for different system and fault conditions. Results demonstrate the accuracy of the proposed method.
\end{abstract}

Keywords: System impedance ratio (SIR), Voltage peak transient, Voltage zero transient, Ferroresonance suppression circuit (FSC), Fault resistance, Protection of transmission line

\section{Introduction}

Directional relay decision is imperative for distance relay to maintain system integrity and stability [1]. However, the decision of directional relay is often affected by the instrument errors [2,3]. CCVT is generally applied in high voltage and extra high voltage system as it is capable of producing the exact replica of the line voltage in the secondary side at lower cost and with improved accuracy. The output response of CCVT is affected by subsidence transient which may contain decaying dc component, high frequency decaying and low frequency decaying components [4]. Under such conditions, the phasor estimation process will be either delayed or erroneous $[3,4]$. The presence of subsidence transient in the secondary side of CCVT is either due to zero voltage fault, high source impedance ratio (SIR), fault with zero resistance path, close-in fault and several other causes such as configuration of ferroresonance suppression circuit (FSC), high burden on the secondary side etc. [5-8]. Fault during single-pole-operation is

* Correspondence: monalisabiswal22@gmail.com

National Institute of Technology, Raipur 492010, Chhattisgarh, India one of many causes behind CCVT subsidence transient $[5,9]$. Fault at voltage zero causes magnitude reduction and a phase angle shift of the CCVT output voltage $[10,11]$. This reduced voltage magnitude if further supplied to directional relay may cause relay maloperation $[7,10]$.

In the past few years, researchers have been developed different CCVT model using various software packages to conduct the transient studies [12-16]. In [17], a detail review of different mathematical models of CCVT to represent the nonlinear behavior of the magnetic core is provided. Also in the literature several phasor estimation techniques have been proposed to reduce the impact of CCVT on distance relay [10, 18]. In [19], the performance report of CVT (capacitive voltage transformer) with electronic FSC under different system and fault conditions is provided. In the literature several mathematical modeling methods, phasor estimation techniques and distance relay algorithms have been reported to mitigate the impact of CCVT subsidence transient. However, no such specific research article providing the solution to mitigate the impact of directional relaying during CCVT 
subsidence transient has been reported. With this motivation, the impact of CCVT subsidence transient generated during single-pole operation on directional relaying is investigated in this work and a solution is provided.

In the literature several techniques have been reported to solve the directional relaying problems of transmission line [20-23]. The algorithms are mainly based on voltage or current information. With large CCVT error correct direction estimation is a challenging task for many relaying algorithm. Sometimes relay correctly see the fault direction but further asserted which causes line relay to operate incorrectly $[5,10]$. Distance relay algorithms are implemented with CCVT transient detection logic [24]. With such facility, new solutions can be provided to avoid relay malfunction. To obtain subsidence transient at the secondary side of CCVT, a new CCVT model is developed in EMTDC/PSCAD environment considering the nonlinear elements. Next, a current based approach is proposed which computes the phase angle difference between positive sequence post fault and prefault current. The impacts of voltage zero transient, voltage peak transient, passive FSC, different faults, fault resistance, high system SIR and fault location on the performance of proposed method are studied and results are compared with conventional techniques.

The rest of the paper is organized as follows: directional relaying challenges with CCVT transient during SPT is described in Section 2. Section 3 explains the different directional methods and the proposed method. Simulation results are presented in Section 4. Finally, the conclusion is drawn in Section 5.

\section{Directional relaying challenges with CCVT transient during single-pole operation}

CCVT is generally applied over high voltage and extra-high voltage transmission system as it is inexpensive and not subject to ferroresonance condition. In modern numerical relays, fundamental voltage and current information based techniques are employed to estimate the actual fault direction. Relay algorithm either requires three phase information or sequence components for fault direction discrimination. Since, during single pole operation unavailability of faulty phase information may create challenges for relaying algorithm sequence component based algorithms are more advantageous as compared to phase information based techniques. However, with such phenomenon the reduced magnitude of sequence voltage computed using remaining healthy phase voltages is a further matter of concern for directional relaying algorithm [5]. Further any fault during such a period introduces transient at the secondary terminal of CCVT known as subsidence transient. Directional relay algorithms which rely on voltage information are affected during such a condition.
In order to demonstrate the directional relaying issues with CCVT transients during SPT condition, a $500 \mathrm{kV}$ $50 \mathrm{~Hz}$ test system [18] as shown in Fig. 1 is considered. In the system, line segments are modeled with distributed parameter in EMTDC/PSCAD. The directional relay at bus $\mathrm{Q}$ is studied in this paper. The current and voltage signals required for directional relay are collected from CT and CCVT secondary having ratios of 1000:5 A and $500 \mathrm{kV}: 110 \mathrm{~V}$ respectively.

A schematic diagram of CCVT model as considered in the study is shown in Fig. 2 [18]. The CCVT is represented by: coupling capacitors $\mathrm{C} 1$ and $\mathrm{C} 2$, series inductance, step-down transformer (SDT). The active and passive ferroresonance suppression circuit models used in CCVT is shown in Fig. 3(a) and (b) respectively $[15-17,25,26]$. The line side CT and CCVT information is considered for the study and comparative assessment. The detailed system parameters are provided in Appendix 1. The internal parameters of CCVT are mentioned in the Appendix 2 [18].

The CCVT is applied over high voltage system for several advantages [26, 27]. However, it is subjected to power system transients followed by faults. The transients at the secondary side of CCVT not present in the primary are introduced by the CCVT internal parameters. The nonlinear internal parameters of CCVT introduce small oscillations but can take the form of large distortions in voltage signal [28]. During steady state condition, the time response of CCVT is an actual replica of the primary side. While, the transient response includes high frequency decaying component, low frequency decaying component and dc decaying component [18]. The presence of various transient components depends on the fault inception point on voltage wave, type of FSC, system SIR, burden, fault resistance and fault location. In Fig. 4, the time response of CCVT including different transient components for any fault during single pole operation is shown. In the figure the transient response of CCVT is compared with the output response of an ideal potential transformer (PT) of same ratio which will not able to generate transient in it secondary output.

Directional relay algorithm based on phasor components either uses voltage or current information as a reference quantity. Negative sequence directional element provides better directional security during SPT condition

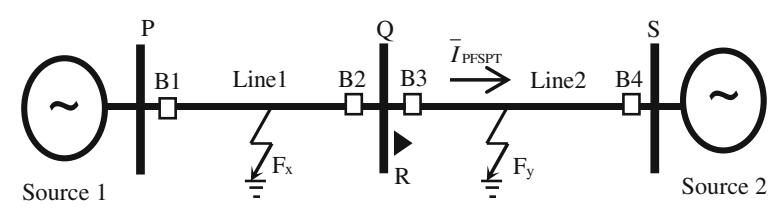

Fig. 1 Simulated three phase power system 


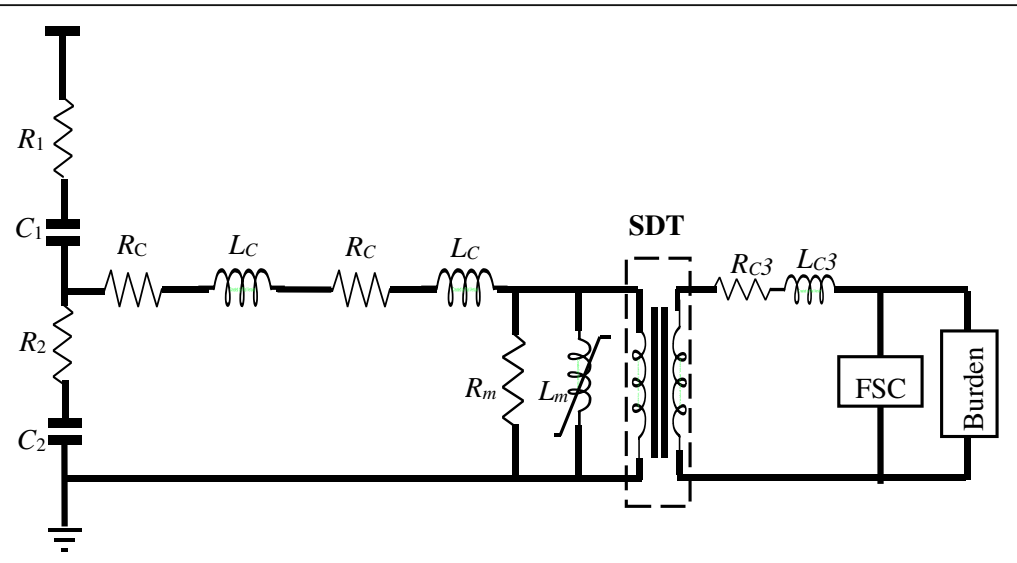

Fig. 2 Schematic diagram of the studied CCVT circuit. (b) Active ferroresoance suppression circuit

[29-32]. However, during high resistance fault the relaying decision based on negative sequence component is not reliable [33]. Relaying algorithm based on line side information finds problem due to CCVT secondary transient. In Fig. 5 the angular plot for negative sequence voltage is provided for reverse side (Fx side) and forward side (Fy) side fault considering the effect of CCVT transient and without transient. Line side CCVT information is considered in the study. For fault in Fy side the negative sequence voltage is shifted more than $90^{\circ}$. This creates problem for directional relay using negative sequence voltage as reference quantity.

Fault direction estimation during SPT condition using positive sequence components can be possible. However, during single pole operation in applications with lineside potential, eventual corruption of polarizing quantity can occur if the input voltage to the memory circuit is corrupted. Invalid memory polarization may cause directional element malfunction. For this reason, the positive

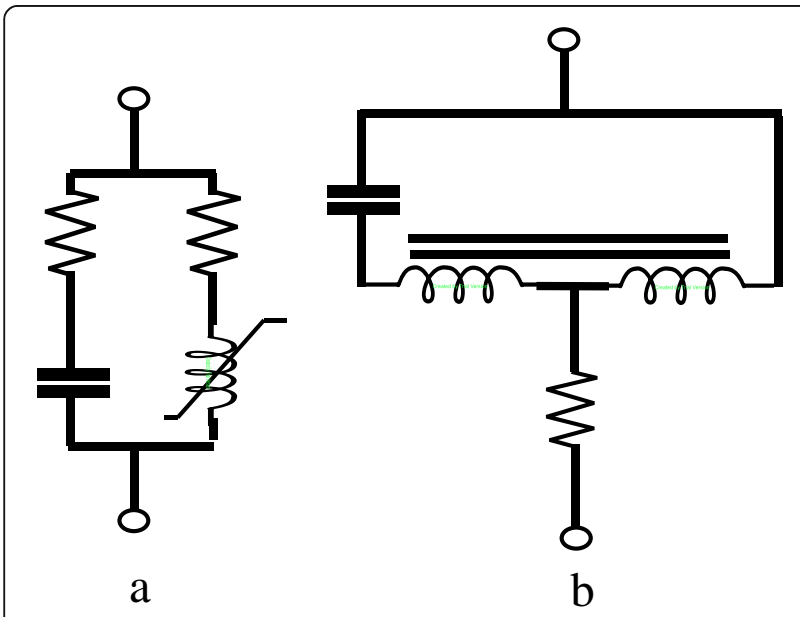

Fig. 3 Schematic diagram of a Passive ferroresoance suppression circuit. b Active ferroresonance circuit sequence voltage input to the polarizing memory is generally eliminated when the voltage is distorted [29]. To overcome from this problem a positive sequence current based approach is proposed in this paper. The method requires only current information measured at relay location to decide whether the fault is in forward side or reverse side. The performance of the method is independent of CT location.

\section{Directional relaying techniques}

\subsection{Conventional directional algorithms}

To detect accurate fault direction different methods are available in the literature. Different directional methods are mentioned below:

\subsubsection{Method-1: Phase angle difference between negative sequence fault current and fault voltage [32]}

First method uses the phase angle difference between negative sequence fault current and fault voltage $\left(\phi_{1}=\angle\right.$ $\left.\bar{I}_{2 \mathrm{FSPT}}-\angle \bar{V}_{2 \mathrm{FSPT}}\right)$. This method is commonly used for directional relaying during SPT condition. The value of $\phi_{1}$ is positive for reverse fault and negative for forward side fault. The placement of CCVT and fault very close to relay location are the two cases which influence the performance of this method.

\subsubsection{Method-2: Phase angle difference between negative sequence fault current and prefault current [30]}

The second method is the angle difference between negative sequence fault current and prefault current $\left(\phi_{2}=\angle\right.$ $\bar{I}_{2 \mathrm{FSPT}}-\angle \bar{I}_{2 \mathrm{PFSPT}}$ ) during SPT. The rule of decision with this method will be that positive angle corresponds to the reverse side fault and negative angle for the forward side fault. Fault with high resistance and high SIR creates problems to this method. 


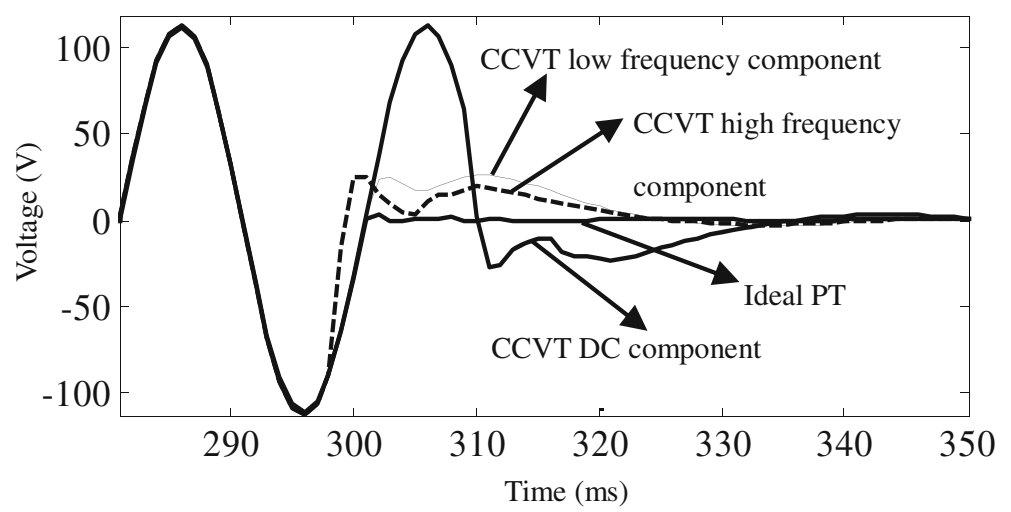

Fig. 4 Time response of both ideal PT and CCVT including different transient components

\subsubsection{Method-3: Phase angle difference between positive sequence superimposed voltage and current [23]}

The third method is the angle between superimposed voltage and current $\left(\phi_{3}=\angle \overline{\Delta V}_{1 \mathrm{SPT}}-\angle \overline{\Delta I}_{1 \mathrm{SPT}}\right)$ during $\mathrm{SPT}$. For reverse side fault the angle is positive and negative for forward fault. Such a method is affected during open pole situation as the memory voltage corrupted. The location CCVT is another source of relay maloperation.

It was projected before that the different voltage information based techniques which are used for directional relaying during SPT condition have limitations due to CCVT transient. Instead of using voltage information, negative sequence based current-only techniques are also preferred during SPT. However, for high system SIR value the negative sequence component based technique will get affected. To solve these problems, in this paper a positive sequence current base approach is proposed as described below.

\subsection{Proposed method}

A subsidence transient appear at the secondary side of CCVT either due to close-in fault or any fault during single-pole operation may be a damped, decaying, oscillatory or unidirectional signal. However, the presence of decaying dc component is more pronounced in subsidence transient [10]. Least square technique is more applicable in power network for filtering the decaying dc component. In this context, to filter the dc component and to extract the fundamental component least square approach is applied in this work.

Fault current signal not only contain fundamental component but also harmonic and decaying dc component. In (1) the mathematical expression of fault current sample at an instant is given where both fundamental and harmonic components are expressed as a sinusoidal function.

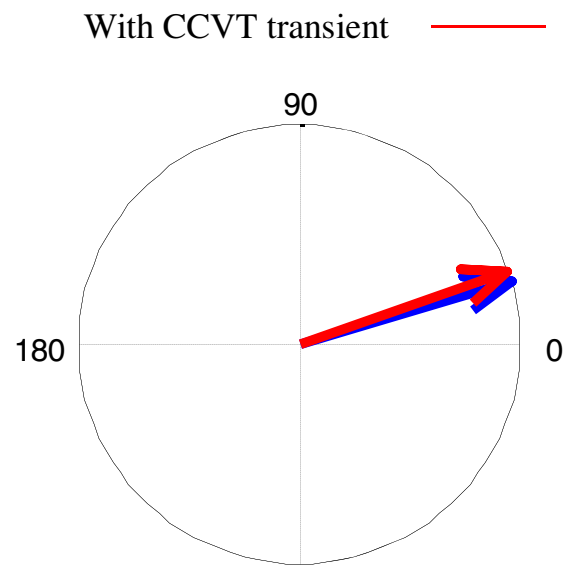

a

\section{Without CCVT transient}

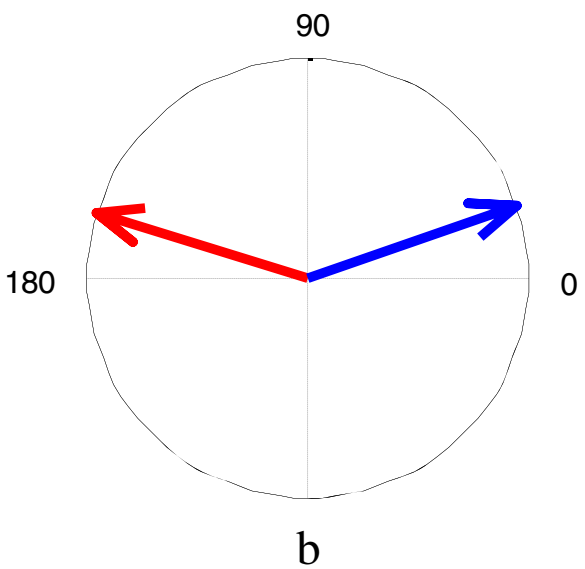

Fig. 5 Angular position of negative sequence voltage at relay location with and without presence of CCVT transient for fault. (a) At $F_{x}$ side. (b) At Fy side 


$$
i(t)=I_{\mathrm{dc}} e^{-k T_{s}} / \tau+I_{\mathrm{m}} \sin \left(k \omega_{0} T_{s}+\varphi\right)
$$

where $I_{\mathrm{dc}}$ is the magnitude of the decaying dc offset at $\mathrm{t}=0, \tau$ is the time constant of the decaying dc offset, $I_{\mathrm{m}}$ is the peak of the fundamental component, $\varphi$ is the phase angle of the fundamental frequency component, $\omega_{0}$ is the fundamental frequency and $T_{s}$ is the sampling interval.

In (1) the fundamental component of current using least square approach can be estimated taking $\mathrm{N}$ number of samples per cycle as described below:

$$
[\mathrm{A}][X]=[\mathrm{B}]
$$

where

$$
\begin{aligned}
& {[\mathrm{A}]=\left[\begin{array}{ccccc}
\sin \left(\omega_{0} T_{s}\right) & \cos \left(\omega_{0} T_{s}\right) & 1 & -T_{s} & T_{s}^{2} \\
\sin \left(\omega_{0} 2 T_{s}\right) & \cos \left(\omega_{0} 2 T_{s}\right) & 1 & -2 T_{s} & \left(2 T_{s}\right)^{2} \\
\cdot & \cdot & 1 & \cdot & \cdot \\
\cdot & \cdot & 1 & \cdot & \cdot \\
\sin \left(\omega_{0} N T_{s}\right) & \cos \left(\omega_{0} N T_{s}\right) & 1 & -N T_{s} & \left(N T_{s}\right)^{2}
\end{array}\right] \text { and }} \\
& {[X]=\left[\begin{array}{lllll}
I_{m} \cos \varphi_{p} & I_{m} \sin \varphi_{p} & k_{0} & \frac{k_{0}}{\tau} & \frac{k_{0}}{2 \tau^{2}}
\end{array}\right]^{\mathrm{T}}}
\end{aligned}
$$

In (2), the vector matrix [B] can be represented as

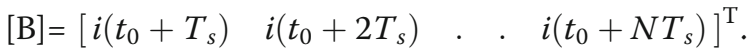

Using least square technique, the unknown parameters in $[\mathrm{X}]$ can be estimated by using

$$
[X]=\left(\left[\mathrm{A}^{\mathrm{T}} \mathrm{A}\right]^{-1} \mathrm{~A}^{\mathrm{T}}\right)[B]=\mathrm{A}^{\dagger}[B]
$$

where $\mathrm{A}^{\dagger}$ is the left pseudoinverse of $\mathrm{A}$. The first two rows of $\mathrm{A}^{\dagger}$ contains the coefficients of sine and cosine digital filters. These two filters can be used to evaluate the fundamental frequency components. With fault inception, all the three phase currents can be calculated as

$$
\hat{X}=X_{\mathrm{c}}+j X_{\mathrm{s}}
$$

where $X_{\mathrm{c}}$ and $X_{\mathrm{s}}$ are the real and imaginary part of $\hat{X}$. During single pole operation the positive sequence current measured at relay location as shown in Fig. 1 will be $\bar{I}_{\text {PFSPT }}$. Further, with any fault during single pole operation either in the upsteam side i.e., in line-1 i.e., or in the downstream side i.e., in line-2, the current calculated at relay location will be $\bar{I}_{\mathrm{FSPT}}$. Using phase angle difference between prefault and fault currents the direction of fault can be discriminated as,

$$
\theta=\left(\left\llcorner\bar{I}_{\mathrm{FSPT}}-\bar{I}_{\mathrm{PFSPT}}\right)=\left\{\begin{array}{l}
+ \text { ve for Fx side fault } \\
\text {-ve for Fy side fault }
\end{array}\right\}\right.
$$

The above relation can be used to discriminate the forward and reverse side fault during CCVT subsidence transient with transmission line in single pole operation.
The flow diagram of the proposed method is shown in Fig. 6.

\section{Simulation results}

The proposed directional algorithm is tested in the system as shown in Fig. 1. The line side CCVT information is used for the relaying algorithm. To create SPT condition a-g fault is created at certain distance in line- 1 and 2. Fault is initiated at $0.3 \mathrm{~s}$ and cleared at $0.4 \mathrm{~s}$ by opening breaker B3 and B4 simultaneously. With single-pole operation further fault in the line causes transient at the secondary side of CCVT. To test the performance of proposed method for transient period during single-pole tripping, different fault cases are simulated using EMTDC/PSCAD. Simulations are carried out for various power system events, such as forward side fault, reverse side fault, fault with different SIR value, voltage zero and voltage peak fault, close-in fault, phase-to-phase fault, ground fault, high resistance fault, end zone fault etc. The AFSC and PFSC are considered separately for the performance evaluation of proposed method. Nonlinear CT model is considered in the simulation. Least square technique with decaying dc component is used for phasor estimation process. Sampling rate is maintained at $1 \mathrm{kHz}$. The performance of proposed method along with different conventional techniques are evaluated and demonstrated below.

\subsection{Impact of voltage zero transient}

To investigate the impact of voltage zero transient on the performance of proposed method, a phase-to-phase fault case is simulated during SPT. B-c fault at $0.3911 \mathrm{~s}$ in both reverse (Fx side) and forward side (Fy side) of relay at a location of $5 \mathrm{~km}$ is simulated. The SIR is considered as 20. Fig. 7a and b compares the dynamic responses of different methods for faults in Fx and Fy side. Using (4) the fundamental voltage and current components of each phase are calculated. For b-c fault in line-1, the value of $\phi_{1}$ is initially positive and inconsistent later. The value of $\phi_{3}$ is in the negative side provides wrong fault direction. Since, both $\phi_{2}$ and $\theta$ are consistently in the positive side indicates the correct direction of fault. The value of $\theta$ is calculated using (5). The response of different methods along with proposed technique is shown in Fig. 7a. Similarly, in Fig. 7b the dynamic responses of different methods for b-c fault at Fy side are provided. For forward side close-in fault during SPT at voltage zero point, negative sequence voltage based methods (method-1) is maloperated. Due to CT saturation, method-2 based on negative sequence current is also getting affected. The output of method-3 based on superimposed components and the proposed method are negative which is clear from Fig. $7 \mathrm{~b}$. The location of CCVT, high SIR and close-in fault condition 


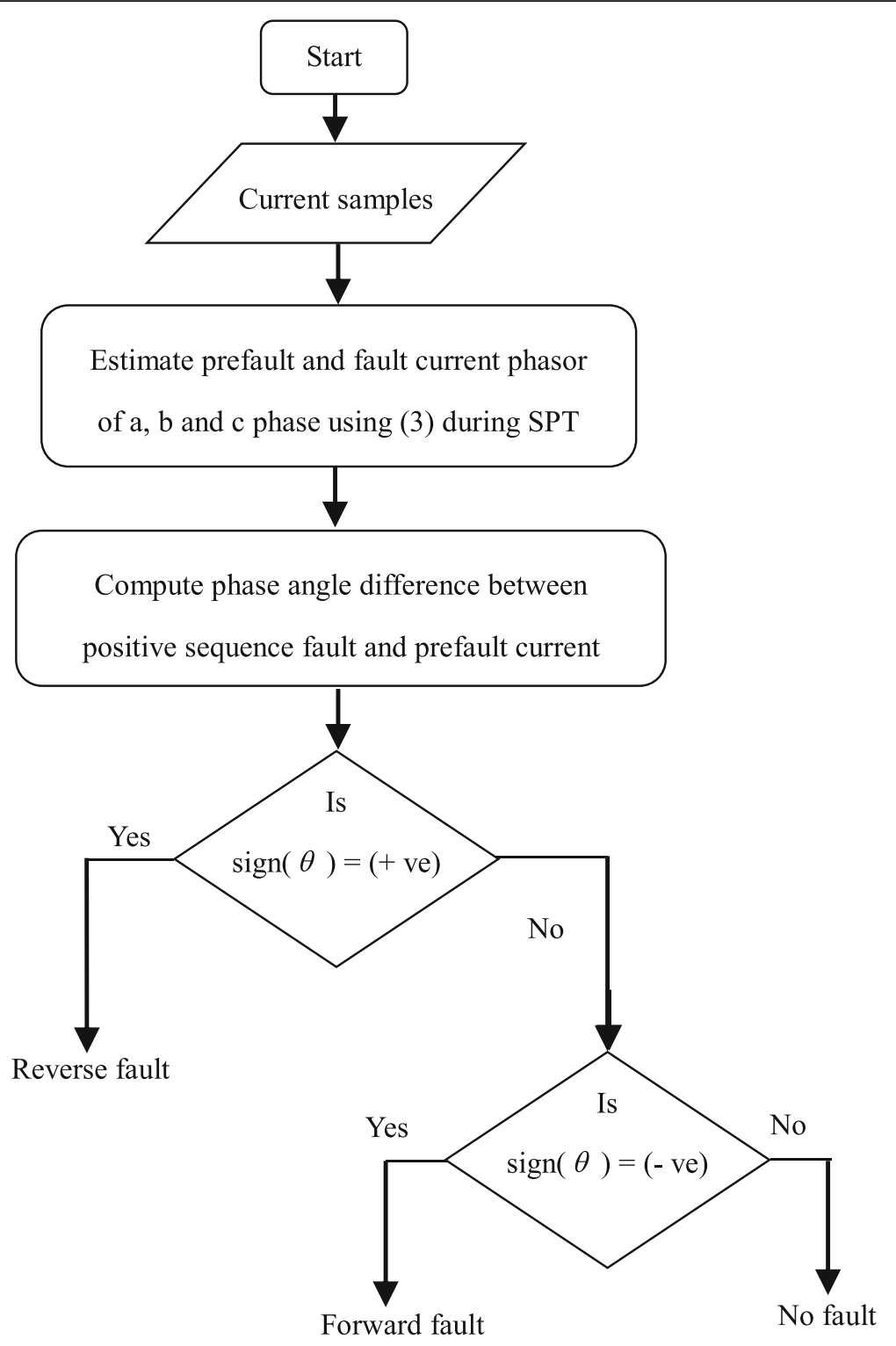

Fig. 6 Flow diagram for discriminating the forward and reverse fault condition

has negative impact on the performance of method-1, 2 and 3 as evident from the Fig. 7. However, the proposed method is not influenced by such conditions. Also it is concluded from the results that during voltage zero transient with single pole breaker operation the proposed method correctly declares the fault direction where other methods are not able to do so.

\subsection{Impact of passive ferroresonance suppression circuit (FSC)}

The impact of passive ferroresonance circuit (PFSC) during different situations and system conditions with SPT operation are investigated in this section. Considering PFSC in CCVT secondary different fault cases are simulated. Phase fault and ground fault at different locations of the line-1 and line-2 (Fig. 1) are created. The system SIR is assumed as 30. The sensitivity of the proposed method is checked for different fault inception angles like $0^{\circ}, 45^{\circ}, 90^{\circ}$ and $180^{\circ}$.

\subsection{Impact of voltage peak transient}

The impact of voltage peak CCVT transient for fault during SPT is investigated in this section. B-g fault at $0.3824 \mathrm{~s}$ on both side of the relay at a distance of $45 \mathrm{~km}$ is created. The fault resistance is considered as $100 \Omega$. SIR is considered as 30 . It should be noted that the ground fault case as shown in Fig. 8a is a worst case in which the voltage peak transient at CCVT secondary affect the performance of method- 1 and 3 which are based on voltage information. The value of $\phi_{2}$ based on 


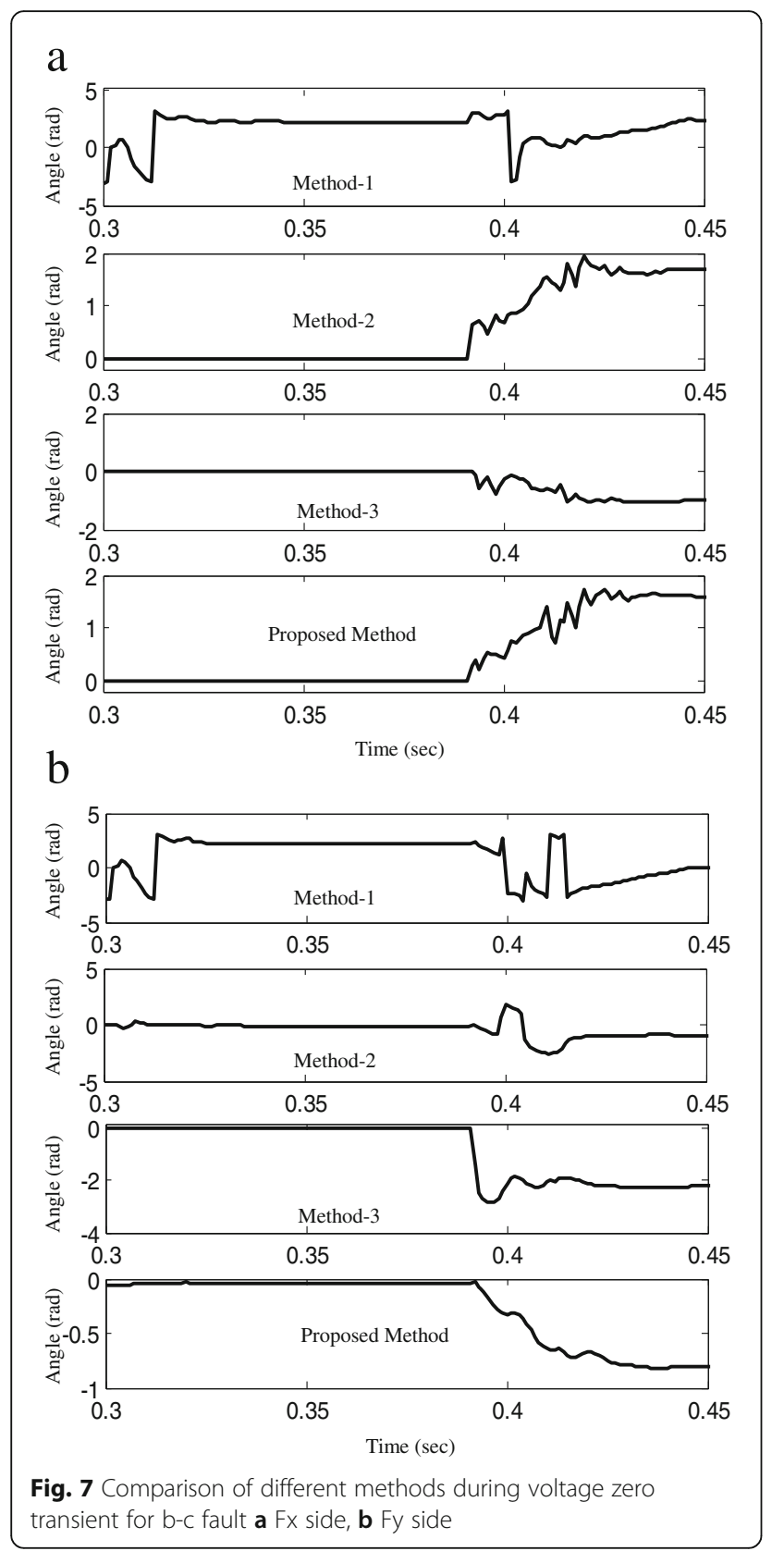

negative sequence fault and prefault current provided positive value for Fx side fault. Using proposed method, for Fx side fault relay measures the angle difference between prefault current during single-pole-operation i.e., $\bar{I}_{\text {PFSPT }}$ and fault current $\bar{I}_{\mathrm{FSPT}}$. So, for this case both the method-2 and proposed method provides correct decision on fault direction as clear from Fig. 8a. In Fig. 8b, the responses of different methods for forward side fault are provided. For this case, all the three methods i.e., method-1, 2 and 3 are failed. The nonlinear response of CT, fault initiation point, location of CCVT, higher SIR and fault resistance have negative impacts on method-1, 2 and 3 . However, the proposed method performs well

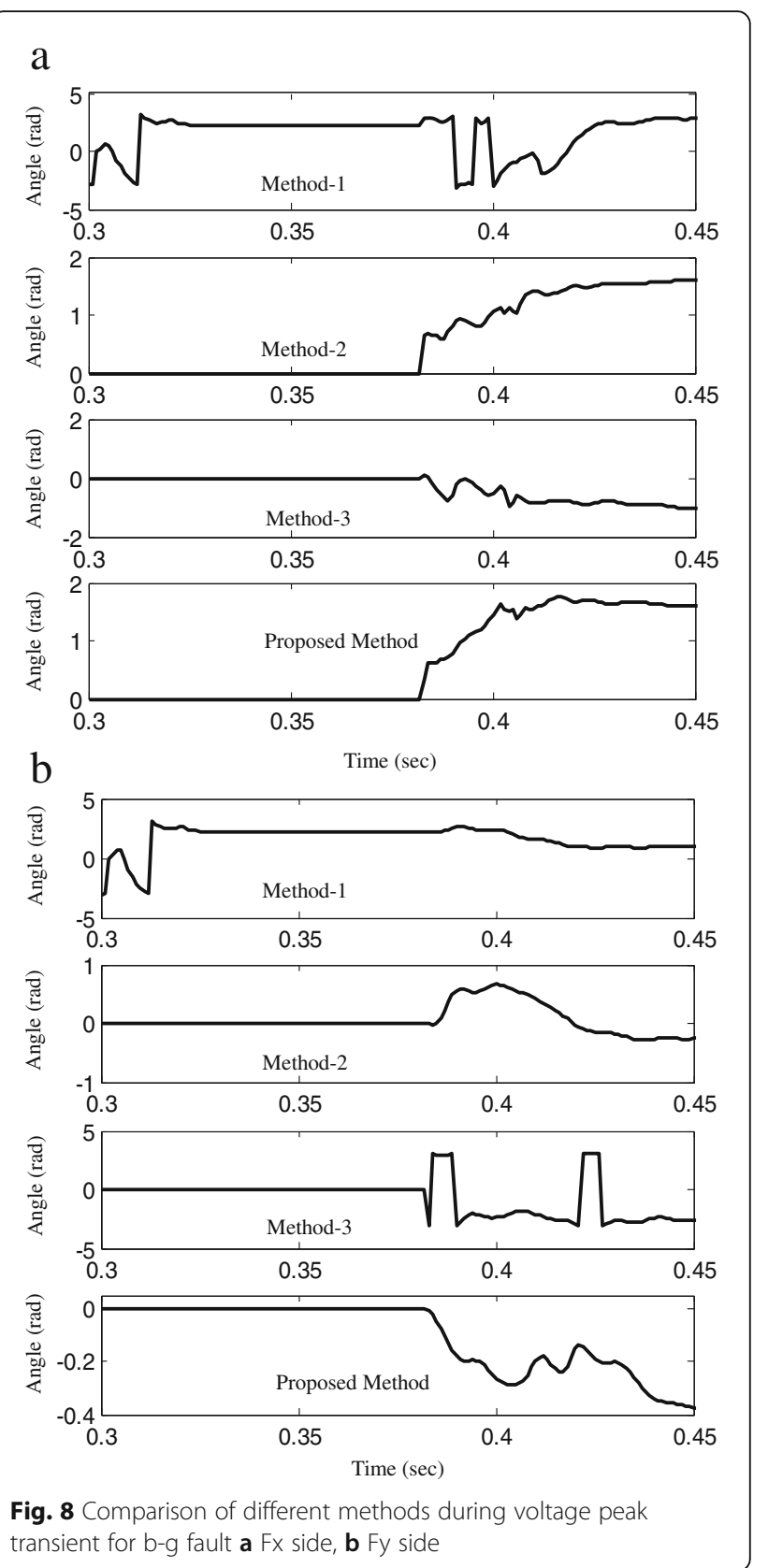

for these conditions also as cleared from Fig. 8b. As, it is a current only based method the impact of CCVT subsidence transient does not affect the relay performance.

\subsection{Impact of end zone fault}

Directional relay decision is often erroneous during end zone faults. Sometimes the CCVT transient is more pronounced during end zone low resistance fault [18]. To see the impact of such a fault case on the performance of proposed method, a single-line-to-ground fault (c-g) at $245 \mathrm{~km}$ from relay terminal is created at Fy side i.e., forward side. The fault resistance is $1 \Omega$. The system SIR 
is assumed to be 30 . Fault is created at 0.4 s i.e., during reclosing period. The responses of method-1, 2, 3 and proposed method are shown in Fig. 9. During an end zone fault at reclosing period, method- 2 and method-3 provides incorrect decision and thus the value of $\phi_{2}$ and $\phi_{3}$ are negative. However, method-1 and proposed method perform correctly as observed from the dynamic response shown in Fig. 9.

In the first case, faults are created at different locations on the line in reverse side and the obtained results are presented in Table-I. In Table-I, the positive values of $\phi_{1}$ and $\phi_{2}$ measured after one cycle of fault inception indicates that the fault is in Fx side i.e., reverse side of relay, which is correct. However, for different fault in reverse side with the presence of PFSC in the circuit during SPT condition, $\phi_{3}$ is consistently negative. This provides wrong information regarding fault direction. Hence, for such a system and fault condition superimposed based technique is not reliable enough. Moreover, the value of $\theta$ calculated using proposed method is consistently positive for different phase-fault in the reverse side of relay. This proves the correct operation of proposed method. From Table 1 it is clear that proposed directional relaying algorithm is not affected by the presence PFSC in CCVT secondary circuit during SPT condition.

Similarly, different single-line-to-ground faults (b-g fault) at different locations in line- 2 are created with different fault inception angles. The SIR is similar to the previous case i.e., 30. Fault resistance is considered as $100 \Omega$. The obtained results are provided in Table 2. $\Phi_{1}$ and $\phi_{2}$ are consistently positive for different b-g faults in the forward side of the relay. This indicates that the fault is in reverse side i.e., Fx side, which is not correct. For

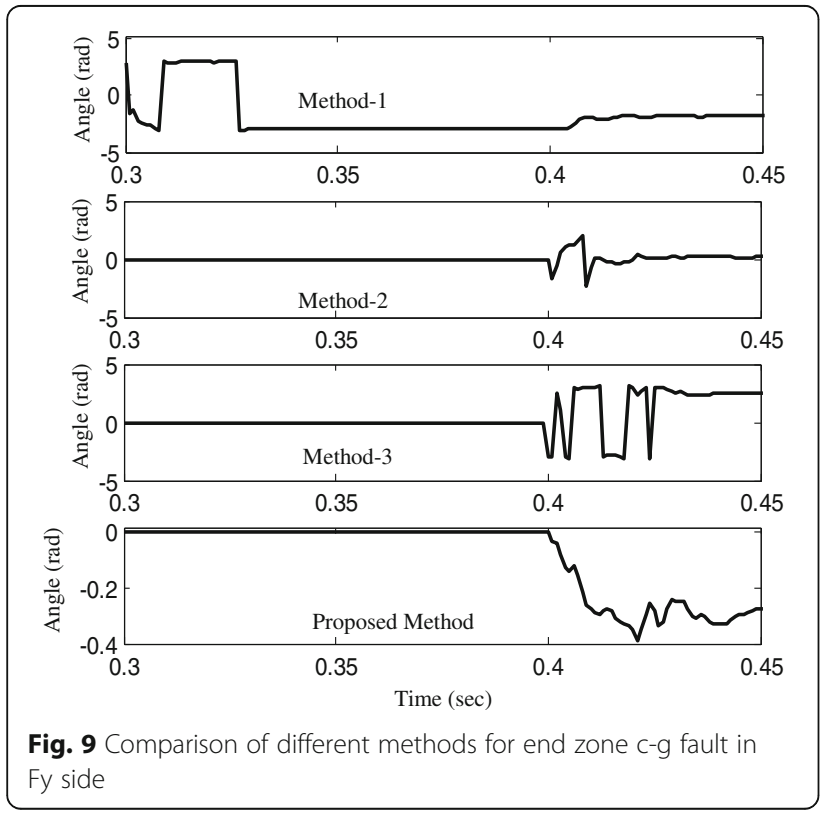

Table 1 Results for b-c in reverse side with PFSC in CCVT secondary, $\mathrm{SIR}=30$

\begin{tabular}{llcccc}
\hline $\begin{array}{l}\text { Fault } \\
\text { location } \\
\text { in km }\end{array}$ & $\begin{array}{l}\text { Fault } \\
\text { inception } \\
\text { Angle }\end{array}$ & Method-1 & Method-2 & Method-3 & $\begin{array}{l}\text { Proposed } \\
\text { method }\end{array}$ \\
\hline 5 & $0^{\circ}$ & 1.951 & 0.6180 & -0.5766 & 0.4580 \\
25 & $0^{\circ}$ & 1.921 & 0.6258 & -0.7199 & 0.4686 \\
45 & $0^{\circ}$ & 2.043 & 0.6677 & -0.4975 & 0.4279 \\
5 & $45^{\circ}$ & 1.956 & 0.5320 & -0.4078 & 0.6206 \\
25 & $45^{\circ}$ & 1.871 & 0.5220 & -0.7646 & 0.5816 \\
45 & $45^{\circ}$ & 1.953 & 0.5269 & -0.4359 & 0.5944 \\
5 & $90^{\circ}$ & 2.271 & 1.023 & -2.274 & 0.228 \\
25 & $90^{\circ}$ & 2.148 & 0.980 & -1.901 & 0.298 \\
45 & $90^{\circ}$ & 2.080 & 0.832 & -2.160 & 0.277 \\
5 & $180^{\circ}$ & 1.735 & 0.640 & -0.549 & 0.454 \\
25 & $180^{\circ}$ & 1.665 & 0.652 & -0.694 & 0.477 \\
45 & $180^{\circ}$ & 1.745 & 0.648 & -0.561 & 0.478 \\
\hline
\end{tabular}

Table 2 Results for b-g in forward side with PFSC in CCVT secondary, $\mathrm{SIR}=30$, fault resistance $=100 \Omega$

\begin{tabular}{|c|c|c|c|c|c|}
\hline \multirow{2}{*}{$\begin{array}{l}\text { Fault } \\
\text { location } \\
\text { in } \mathrm{km}\end{array}$} & \multirow{2}{*}{$\begin{array}{l}\text { Fault } \\
\text { inception } \\
\text { angle }\end{array}$} & \multirow{2}{*}{$\begin{array}{l}\text { Method-1 } \\
\phi_{1}(\mathrm{rad})\end{array}$} & \multirow{2}{*}{$\begin{array}{l}\text { Method-2 } \\
\phi_{2} \text { (rad) }\end{array}$} & \multirow{2}{*}{$\begin{array}{l}\text { Method-3 } \\
\phi_{3}(\mathrm{rad})\end{array}$} & \multirow{2}{*}{$\begin{array}{l}\text { Proposed } \\
\text { method } \\
\theta \text { (rad) }\end{array}$} \\
\hline & & & & & \\
\hline 5 & $0^{\circ}$ & 1.474 & 0.0221 & -2.783 & -0.053 \\
\hline 25 & $0^{\circ}$ & 1.675 & 0.2674 & -2.365 & -0.107 \\
\hline 100 & $0^{\circ}$ & 1.680 & 0.0008 & -2.429 & -0.153 \\
\hline 200 & $0^{\circ}$ & 1.972 & 0.6303 & -2.257 & -0.108 \\
\hline 245 & $0^{\circ}$ & 1.836 & 0.7106 & -2.743 & -0.262 \\
\hline 5 & $45^{\circ}$ & 1.843 & 0.4704 & 2.994 & -0.140 \\
\hline 25 & $45^{\circ}$ & 1.852 & 0.5514 & -3.059 & -0.170 \\
\hline 100 & $45^{\circ}$ & 1.676 & 0.5335 & -2.204 & -0.177 \\
\hline 200 & $45^{\circ}$ & 1.702 & 0.5531 & -1.915 & -0.133 \\
\hline 245 & $45^{\circ}$ & 1.717 & 0.4896 & -2.615 & -0.194 \\
\hline 5 & $90^{\circ}$ & 1.691 & 0.3730 & -3.051 & -0.127 \\
\hline 25 & $90^{\circ}$ & 1.575 & 0.3495 & -2.192 & -0.070 \\
\hline 100 & $90^{\circ}$ & 1.511 & 0.3928 & -1.887 & -0.090 \\
\hline 200 & $90^{\circ}$ & 1.999 & 0.8744 & -2.838 & -0.259 \\
\hline 245 & $90^{\circ}$ & 1.659 & 0.4606 & 2.902 & -0.228 \\
\hline 5 & $180^{\circ}$ & 1.235 & 0.0187 & 2.572 & -0.057 \\
\hline 25 & $180^{\circ}$ & 1.541 & 0.3977 & 2.790 & -0.135 \\
\hline 100 & $180^{\circ}$ & 1.518 & 0.4808 & -2.490 & -0.181 \\
\hline 200 & $180^{\circ}$ & 1.706 & 0.6632 & -2.267 & -0.155 \\
\hline 245 & $180^{\circ}$ & 1.779 & 0.5900 & 2.278 & -0.172 \\
\hline
\end{tabular}


such a fault case, from the different obtained values $\phi_{3}$ and $\theta$ as provided in Table 2, it is clear that method-3 fails during five cases. However, the proposed method correctly sees the fault direction as the value of $\theta$ is consistently negative (in Table 2) for different fault inception angle and fault location. This shows that the positive sequence current based method is immune to the influence of PFSC, fault inception angle and higher SIR value.

\subsection{Results for various faults}

The performance of proposed method is evaluated for various fault cases such as single-line-to-ground fault, double-line fault, and double-line-to-ground fault at different locations on the line. Fault is created at both forward and reverse side of the relay. Results are provided for different SIR values, such as 1, 2, 5, 10, 20 and 30. For reverse side fault resistance is assumed as $1 \Omega$ whereas, for forward side $50 \Omega$.

In Table 3, the simulation results for different reverse side faults initiated during reclosing period are presented. A shown in Table 3, the proposed method provides correct decision for different SIR values. In all reverse side fault conditions, the value of $\theta$ is consistently positive.

In Table 4, the simulation results for different forward side faults initiated during reclosing period are presented. The performance of the proposed method does not adversely affected by the fault location and fault type which is clear from Table 4. For worst system condition $(\mathrm{SIR}=30)$ when the chance of CCVT subsidence transient is more prominent [34], the proposed method operate correctly i.e., $\theta$ is negative. This indicates forward side fault.

So, it is clear from the results that the proposed directional relaying method based on phase angle difference of fault to prefault positive sequence current has satisfactory performance for different critical system and

Table 3 Results for different forward side fault during singlepole-tripping

\begin{tabular}{lllllll}
\hline Fault type & $\begin{array}{l}\text { Fault } \\
\text { location } \\
\text { in km }\end{array}$ & \multicolumn{6}{l}{$\theta$ (rad), Fault resistance $=1 \Omega$} & \\
\cline { 3 - 7 } & $\mathrm{SIR}=0.2$ & $\mathrm{SIR}=1$ & $\mathrm{SIR}=5$ & $\mathrm{SIR}=10$ & $\mathrm{SIR}=30$ \\
\hline b-g & 5 & 1.098 & 1.728 & 1.774 & 1.794 & 1.804 \\
b-g & 25 & 1.119 & 1.745 & 1.790 & 1.809 & 1.819 \\
b-g & 45 & 1.757 & 1.749 & 1.801 & 1.823 & 1.835 \\
bc & 5 & 1.747 & 1.984 & 1.995 & 1.998 & 2.003 \\
bc & 25 & 1.742 & 1.988 & 1.998 & 2.001 & 2.005 \\
bc & 45 & 1.745 & 1.989 & 2.00 & 2.004 & 2.009 \\
bc-g & 5 & 1.786 & 1.993 & 1.995 & 1.997 & 1.998 \\
bc-g & 25 & 1.796 & 2.00 & 2.003 & 2.004 & 2.006 \\
bc-g & 45 & 1.820 & 2.001 & 2.007 & 2.009 & 2.011 \\
\hline
\end{tabular}

Table 4 Results for different reverse side fault during singlepole-tripping

\begin{tabular}{lllllll}
\hline Fault type & $\begin{array}{l}\text { Fault } \\
\text { location } \\
\text { in km }\end{array}$ & \multicolumn{6}{l}{$\theta$ (rad), Fault resistance $=50 \Omega$} & \\
\cline { 3 - 7 } & $\mathrm{SIR}=0.2$ & $\mathrm{SIR}=1$ & $\mathrm{SIR}=5$ & $\mathrm{SIR}=10$ & $\mathrm{SIR}=30$ \\
\hline $\mathrm{c}-\mathrm{g}$ & 5 & -0.4201 & -0.5444 & -0.6910 & -1.034 & -1.276 \\
$\mathrm{c}-\mathrm{g}$ & 100 & -0.4213 & -0.4160 & -0.6337 & -0.8548 & -1.294 \\
$\mathrm{c}-\mathrm{g}$ & 200 & -0.4290 & -0.4290 & -0.6120 & -1.0557 & -1.380 \\
$\mathrm{c}-\mathrm{g}$ & 245 & -0.4107 & -0.4107 & -0.6094 & -0.8571 & -1.318 \\
bc & 5 & -0.6531 & -0.8536 & -0.9889 & -1.0347 & -1.096 \\
bc & 100 & -0.7162 & -0.7149 & -0.9585 & -1.012 & -1.156 \\
bc & 200 & -0.7051 & -0.7051 & -0.9247 & -0.9723 & -0.944 \\
bc & 245 & -0.6844 & -0.6844 & -0.8693 & -0.8940 & -0.969 \\
bc-g & 5 & -0.5217 & -0.7392 & -0.9371 & -1.0310 & -1.223 \\
bc-g & 100 & -0.5728 & -0.5715 & -0.8904 & -0.9608 & -1.157 \\
bc-g & 200 & -0.5839 & -0.5839 & -0.8081 & -0.8364 & -0.808 \\
bc-g & 245 & -0.5730 & -0.5730 & -0.7894 & -0.8315 & -0.892 \\
\hline
\end{tabular}

fault conditions. CCVT subsidence transient during SPT condition is not an issue for this method as it is independent of voltage information. Also the other factors like fault on voltage point of wave, CT saturation, high SIR value, fault location and fault inception angle are not a cause of error for the method as cleared from the results.

\section{Conclusions}

CCVT subsidence transient is a major reason behind the directional relay malfunction. Fault during single-poletripping is one of many causes of CCVT secondary subsidence transient. Conventional directional techniques based on voltage information are affected by transient condition. Negative sequence based directional relaying methods are not reliable for higher SIR system condition.

In this paper, a positive sequence current based directional relaying method is proposed for CCVT secondary transient during SPT condition. The method computes the fundamental components of fault and prefault current using least square technique. Then phase angle difference of fault and prefault positive sequence current is calculated for fault directional estimation. The positive sequence current based methods have although limitation for high resistance far end fault, and load change situation but during such situation CCVT transient is not possible. So, once the CCVT transient at the secondary side is detected, the proposed method can be applied as a stand-alone protection scheme to avoid any nuisance directional relay operation. The presence of AFSC and PFSC, higher system SIR value, fault type, fault location, fault resistance, and fault inception angle have negligible impact on the performance of proposed method. The proposed method is $100 \%$ efficient for 
CCVT subsidence transient condition as based only current information. Results demonstrate the promise of the proposed method.

\section{Appendix 1}

Three phase, $50 \mathrm{~Hz}$ power system (Fig. 1).

System Voltage: $500 \mathrm{kV}$

Load Angle ( $\delta$ ): $30^{\circ}$

Line-1 length: $50 \mathrm{~km}$

Line-2 length: $250 \mathrm{~km}$

CT ratio: 1000/5 A

CCVT ratio:500 kV/110V

Line Parameters:

Positive Sequence Impedance: $(0.1548+\mathrm{j} 0.3050) \Omega / \mathrm{km}$

Negative Sequence Impedance: $(0.1548+\mathrm{j} 0.3050) \Omega / \mathrm{km}$

Zero Sequence Impedance: $(0.3743+$ j 0.9429) $\Omega / \mathrm{km}$

Positive Sequence Shunt Capacitive Reactance: 0.26326

$\mathrm{M} \Omega . \mathrm{km}$

Zero Sequence Shunt Capacitive Reactance: 0.42473

$\mathrm{M} \Omega . \mathrm{km}$

Source Impedance $=$ SIR* Total line impedance

\section{Appendix 2}

\section{CCVT Parameters}

Capacitor Divider:

$\mathrm{R}_{1}=3310.7 \Omega, \mathrm{C} 1=0.001605 \mu \mathrm{F}, \mathrm{R}_{2}=59.0338 \Omega, \mathrm{C}_{2}=$ $0.089991 \mu \mathrm{F}$. Inductance: $\mathrm{R}_{\mathrm{E}}=950.06 \Omega, \mathrm{L}_{\mathrm{E}}=67.922 \mathrm{H}$.

Step Down Transformer: $\mathrm{R}_{\mathrm{P}}=850.02 \Omega, \mathrm{L}_{\mathrm{P}}=4.4433 \mathrm{H}$, $\mathrm{RS}=0.2467 \Omega, \mathrm{L}_{\mathrm{S}}=0.00064991 \mathrm{H}, \mathrm{SDT}$ ratio $=75.8503$.

Ferroresonance Suppression Circuit: $\mathrm{R}_{1 \mathrm{~F}}=0.08 \Omega, \mathrm{R}_{2 \mathrm{~F}}=$ $1.2301 \Omega, C_{1 F}=165.36 \mu \mathrm{F}, \mathrm{L}_{1 \mathrm{~F}}=0.0543 \mathrm{H}, \mathrm{R}_{3 \mathrm{~F}}=13.333 \Omega$.

CCVT Burden ( 1 VA): $R_{1 \mathrm{~B}}=24227.73 \Omega, \quad \mathrm{R}_{1 \mathrm{~B}}=$ $10870.9 \Omega, \mathrm{L} 1 \mathrm{~B}=0.04994 \mathrm{mH}$.

\section{Funding}

The work is not supported by any funding agency. This is the authors own research work.

\section{Authors' contributions}

M Biswal contributed to the conception of the study and helped to draft the manuscript. S Biswal contributed the modeling of CCVT and power system, manuscript preparation, result analysis and wrote manuscript. Both authors read and approved the final manuscript.

\section{Competing interests}

The authors declare that they have no competing interests.

Received: 13 September 2016 Accepted: 7 February 2017 Published online: 15 March 2017

\section{References}

1. Ziegler, G. (2006). Numerical Distance Protection Principles and Applications, Siemens.

2. Elmore, W. A. (1994). Protective relaying theory and applications: ABB Power $T$ \&D Company Inc.

3. Horowitz, S. H., \& Phadke, A. G. (2008). Power System Relaying: John Wiley \& Son.

4. Working Group of the Relay Input Sources Subcommittee of the Power System Relay Committee. (1981). Transient response of coupling capacitor voltage transformers. IEEE Transactions on Power Apparatus and Systems, 100, 4811-4814.
5. Costello, D., \& Zimmerman, K. (2012). CVT transients revisited - distance, directional overcurrent, and communications-assisted tripping concerns (pp. 73-84). College Station: 65th Annual Conference for Protective Relay Engineers.

6. Khanna, A. (2011). Method to improve transient performance of CVTs: Analysis and recommendations. European Transactions on Electrical Power, 21, 1673-1688.

7. Hou, D., \& Roberts, J. (1996). Capacitive voltage transformers: Transient overreach concerns and solutions for distance relaying (pp. 119-125). Calgary: In Proc. Can. Conf. Elect. Comput. Eng.

8. Aboul-Zaheb, E. M., Eldin, E. S. T., Ibrahim, D. K., \& Saleh, S. M. (2007). High impedance fault detection in mutually coupled double-ended transmission lines using high frequency disturbances (pp. 24-28). Tampa: In Proc. International of the IEEE Power Engineering Society, General Meeting.

9. Bakar, H. A., Khan, S. A., Kwang, T. C., \& Rahim, N. A. (2015). A review of ferroresonance in capacitive voltage transformer. IEEJ Transactions on Electrical and Electronic Engineering, 10, 28-35.

10. Ajaei, F. B., Pasand, M. S., Davarpanah, M., Zare, A. R., \& Iravani, R. (2012). Mitigating the impacts of CCVT subsidence transients on the distance relay. IEEE Transactions on Power Delivery, 27, 497-505.

11. Angell, D., \& Hou, D. (2007). Input source error concerns for protective relays (pp. 63-70). College Station: 60th Annual Conference for Protective Relay Engineers.

12. Ajaei, F. B., Sanaye-Pasand, M., \& Rezaei-Zare, A. (2009). Iravani, R. (2009). Analysis and suppression of the coupling capacitor voltage transformer ferroresonance phenomenon. IEEE Transactions on Power Delivery, 24, 1968-1977. doi:10.1109/TPWRD.2009.2028818.

13. Fernandes, D., Jr., Neves, W. L. A., \& Vasconcelos, J. C. A. (2007). Coupling capacitor voltage transformer: A model for electromagnetic transient studies. Electric Power Systems Research, 77, 125-134.

14. Iravani, M. R., Wang, X., Polishchuk, I., Ribeiro, J., \& Sarshar, A. (1998). Digital time-domain investigation of transient behaviour of coupling capacitor voltage transformer. IEEE Transactions on Power Delivery, 13, 622-629.

15. Kezunovic, M., Kojovic, L. J., Skendzic, V., Fromen, C. W., Sevcik, D. R., \& Nilsson, S. L. (1992). Digital models of coupling capacitor voltage transformers for protective relay transient studies. IEEE Transactions on Power Delivery, 12, 1927-1935.

16. Lucas, J. R., McLaren, P. G., Keerthipala, W. W. L., \& Jayasinghe, R. P. (1992). Improved simulation models for current and voltage transformers in relay studies. IEEE Transactions on Power Delivery, 7, 152-159.

17. Working Group C-5 of the Systems Protection Subcommittee of the IEEE Power System Relaying Committee. (2000). Mathematical models for current, voltage, and coupling capacitor voltage transformers. IEEE Transactions on Power Delivery, 15, 62-72.

18. Pajuelo, E., Ramakrishnan, G., \& Sachdev, M. S. (2008). Phasor estimation technique to reduce the impact of coupling capacitor voltage transformer transients. IET Generation Transmission and Distribution, 2, 588-599.

19. Venkatesh, C. \& Shanti Swarup, K. (2014). Performance assessment of distance protection fed by capacitor voltage transformer with electronic ferro-resonance suppression circuit. Electric Power Systems Research, 12, 12-19.

20. Gu, B., Tan, J., \& Wei, H. (2014). High speed directional relaying algorithm based on the fundamental frequency positive sequence superimposed components. IET Generation Transmission and Distribution, 8, 1211-1220.

21. Jalilian, A., Hagh, M. T., \& Hasemi, S. M. (2014). An innovative directional relaying scheme based on postfault current. IEEE Transactions on Power Delivery, 29, 2640-2647.

22. Fleming, B. (1998). Negative sequence impedance directional element. https://www.selinc.com/api/download/2475?id=2475.

23. Biswal, M., Pati, B. B., \& Pradhan, A. K. (2013). Directional relaying for double circuit line with series compensation. IET Generation, Transmission \& Distribution, 7, 405-413.

24. Instruction Manual. (2006). SEL-421 Relay Protection and Automation System, SEL, 2011

25. Graovac, M., Iravani, R., Wang, X., \& McTaggart, R. D. (2003). Fast ferroresonance suppression of coupling capacitor voltage transformers. IEEE Transactions on Power Delivery, 18, 158-163.

26. ANSI C93.1-1999. (1999). American National Standard Requirements for Power-Line Carrier Coupling Capacitors and Coupling Capacitor Voltage Transformers (CCVT).

27. Electricity Association Services Limited. (1995). Power system protection-1. London: The Institution of Electrical Engineers. 
28. Hernandez, J. C., De La Cruz, J., Vidal, P. G., \& Ogayar. (2013). B. Conflicts in the distribution network protection in the presence of large photovoltaic plants: The case of ENDESA. International Transactions on Electrical Energy System, 23(5), 669-688.

29. Calero, F., \& Hou, D. (2004). Practical considerations for single-pole-trip line-protection schemes. In Proc. Of the 31st Annual Western Protective Relay Conference, Spokane, WA, October.

30. Jena, P., \& Pradhan, A. K. (2013). Directional relaying during single-pole tripping using phase change in negative-sequence current. IEEE Transactions on Power Delivery, 28, 1548-1557. doi:10.1109/TPWRD.2013.2258687.

31. Roberts, J., Guzman, A. Directional element design and evaluation. https://selinc.com/api/download/2399/.

32. Zhang, C., Tan, J., \& Gu, B. (2015). A novel negative sequence reactance based high speed directional relay algorithm. International Transactions on Electrical Energy System, 25(10), 2443-2454. doi:10.1002/etep.1972.

33. Mooney, J., Jackie Peer, P.E. Application Guidelines for Ground Fault Protection. https://selinc.com/api/download/2469/.

34. Reis, R. L. A., Lopes, F. V., Neves, W. L. A., \& Fernandes, D., Jr. (2015). Influence of coupling capacitor voltage transformers on travelling wave-based fault locators (pp. 119-125). Cavtat: In Proc. International Conference on Power Systems Transients (IPST2015).

\section{Submit your manuscript to a SpringerOpen ${ }^{\circ}$ journal and benefit from:}

- Convenient online submission

- Rigorous peer review

- Immediate publication on acceptance

- Open access: articles freely available online

- High visibility within the field

- Retaining the copyright to your article

Submit your next manuscript at $>$ springeropen.com 